\title{
O Grupo Philos Sophias: devir filosófico para uma estética da existência singular plural
}

\author{
El Grupo Philos Sophias: devir filosófico para uma estética de la \\ existencia singular plural \\ The Philos Sophias Group: philosophical devir for an aesthetic of singular \\ plural existence
}

\author{
Dulce Mari da Silva Voss ${ }^{1}$ \\ Semíramis Martins Corrêa ${ }^{2}$ \\ Débora do Couto Pereira ${ }^{3}$ \\ Clarice Gomes de Almeida ${ }^{4}$
}

\begin{abstract}
Resumo
Escrevemos sobre o Projeto Filosofias Contemporâneas de Foucault, Nietzsche e Deleuze, desenvolvido pelo Grupo de Pesquisa Philos Sophias que reúne pesquisadores/as e profissionais de distintas áreas de formação acadêmica para o compartilhamento de leituras e conversações. Consideramos que o Projeto vem traçando um território aberto de produção de pensamentos múltiplos e singulares, mediante a articulação dos conceitos filosóficos estudados com os saberes, experiências, desejos de cada um/a dos/as integrantes do grupo. As diferenças nos tornam intercessores uns dos outros numa ação filosófica criadora de devires nas formas de pensar, estar e viver no mundo presente. Experimentar o pensamento livre na produção de uma estética da existência, concebida pela pluralidade e singularidade das subjetividades, é o que nos move. Queremos viver o cuidado de si nas relações com os outros, filosofando.
\end{abstract}

Palavras-Chave: cuidado de si, estética da existência, filosofias contemporâneas, pluralidade, singularidade.

\section{Resumen}

Escribimos sobre el Proyecto Filosofias Contemporaneas de Focault, Nietzsche y Deleuze, desarrollado por el Grupo de Pesquisa Philos Sophias que reúne pesquisadores y profesionales de diferentes áreas de formacion academicas para intercambio de lecturas y conversaciones. Consideramos que El Proyecto viene demarcando un territorio abierto de produccion de pensamientos multiples y singulares, mediante la articulacion de conceptos filosóficos estudiados con los saberes, experiencias y deseos de cada un de los integrantes del grupo.

\footnotetext{
1 Doutora em Educação; Professora do Programa de Pós-Graduação Mestrado Acadêmico em Ensino da Universidade Federal do Pampa Campus Bagé; Bagé, Rio Grande do Sul, Brasil; dulce.voss@gmail.com. Trabalho apresentado no III Encontro Humanístico Multidisciplinar e II Congresso Latino-Americano de Estudos Humanísticos Multidisciplinares, Jaguarão/RS, Brasil, 2017.

${ }^{2}$ Especialista em Educação e Diversidade Cultural; Mestranda do Programa de Pós-Graduação Mestrado Acadêmico em Ensino da Universidade Federal do Pampa Campus Bagé; Bagé, Rio Grande do Sul, Brasil; semíramis_mc@hotmail.com.

${ }^{3}$ Especialista em Educação e Diversidade Cultural; Mestranda do Programa de Pós-Graduação Mestrado Acadêmico em Ensino da Universidade Federal do Pampa Campus Bagé; Bagé, Rio Grande do Sul, Brasil; d.coutopereira@gmail.com.

${ }^{4}$ Especialista em Educação e Diversidade Cultural; Mestranda do Programa de Pós-Graduação Mestrado Acadêmico em Ensino da Universidade Federal do Pampa Campus Bagé; Bagé, Rio Grande do Sul, Brasil; claric.gomes@hotmail.com.
} 
Las diferencias nos tornan intercepsores unos de los otros, en una accion filosófica criadora de devires nas formas de pensar, estar y vivir en el mundo presente. Experimentar el pensamiento libre en la produccion de una estética de la existencia, concebida por la pluralidad y singularidad de las subjetividades, es lo que nos mueve. Queremos vivir el cuidado de si en las relaciones con los otros, filosofando.

Palabras-claves: Cuidado de si, estética de la existência, filosofias contemporâneas, plurarlidad, singularidad.

\begin{abstract}
We write about the Contemporary Philosophies Project of Foucault, Nietzsche and Deleuze, developed by the Philos Sophias Research Group, which brings together researchers and professionals from different fields of academic formation for the sharing of readings and conversations. We consider that the Project has been tracing an open territory of production of multiple and singular thoughts, through the articulation of the studied philosophical concepts with the knowledge, experiences, desires of each one of the members of the group. Differences make us intercessors of each other in a philosophical action that creates devires in the ways of thinking, being and living in the present world. To experience free thought in the production of an aesthetic of existence, conceived by the plurality and uniqueness of subjectivities, is what moves us. We want to live caring for each other in relationships with others, philosophizing.
\end{abstract}

Keywords: care of self, aesthetics of existence, contemporary philosophies, plurality, uniqueness.

\title{
1. Introdução
}

Como nos diz Deleuze (1992, p. 17): "Escrever é um fluxo entre outros, sem nenhum privilégio em relação aos demais e que entra em relação de corrente, contra-corrente de redemoinhos com outros fluxos". Portanto, é para fazer deslizar o fluxo de nossas experimentações filosóficas que escrevemos aqui sobre o Projeto Filosofias Contemporâneas, desenvolvido pelo Grupo de Pesquisa Philos Sophias, enquanto acontecimento que promove o compartilhamento de leituras e conversações.

Nosso grupo formou-se como um desdobramento do Curso de Especialização em Educação e Diversidade Cultural da Universidade Federal do Pampa (UNIPAMPA, Campus Bagé), no período de 2014-2015, momento em que nós discentes iniciamos os estudos das teorias pós-modernas trabalhadas pela docente que hoje é nossa orientadora no Mestrado Acadêmico em Ensino, nessa mesma instituição. Desde então, exploramos novos territórios com essas lentes teóricas na busca de desmitificar verdades absolutas, reconfigurar nossas ações e discursos, como um eterno retorno que não se repete, mas se transforma em múltiplas direções. As Filosofias Contemporâneas compartilhadas pelo Grupo Philos suscitam múltiplos questionamentos sem a pretensão de alcançar uma totalidade, mas sim fazer proliferar as individualidades, singularidades. Exercícios de pensamentos múltiplos que provocam constantes rupturas com as "certezas da cultura moderna ocidental”, estabelecem contradições, reversos de um "ser humano pleno", estratificam nossas visões, constituem desvios, linhas de fuga que nos afectam. 
Somos movidas pelo desejo de uma filosofia que vai além do pragmático e faz da leitura e da escuta o lugar de fruição de pensamentos singulares e múltiplos, sem a pretensão de uma verdade, como diz o poeta: "Buscas a perfeição? Não sejas vulgar. A autenticidade é muito mais difícil” (QUINTANA, 1973, p.211).

É assim a razão de existir do Grupo de Pesquisa Philos Sophias, força que move, vontade de potência, replicando as palavras de Nietzsche (1999, p. 469-450):

\begin{abstract}
Este mundo: uma monstruosidade de força, sem início, sem fim; uma firme, brônzea grandeza de força, que não se torna maior, nem menor, que não se consome, mas apenas se transmuda, inalteravelmente grande em seu todo; uma economia sem despesas e perdas, mas também sem acréscimo, ou rendimentos, cercada de "nada" como de seu limite, nada de evanescente, de desperdiçado; nada de infinitamente extenso, mas como força determinada posta em um determinado espaço, e não em um espaço que em alguma parte estivesse "vazio", mas antes como força por toda parte; como jogo de forças e ondas de força, ao mesmo tempo um e múltiplo, aqui acumulando-se e ao mesmo tempo ali minguando; um mar de forças tempestuando e ondulando em si próprias, eternamente mudando, eternamente recorrentes; com descomunais anos de retorno, com uma vazante e enchente de suas configurações, partindo das mais simples às mais múltiplas, do mais quieto, mais rígido, mais frio, ao mais ardente, mais selvagem, mais contraditório consigo mesmo; e depois outra vez voltando da plenitude ao simples, do jogo de contradições de volta ao prazer da consonância, afirmando ainda a si próprio, nessa igualdade de suas trilhas e anos; abençoando a si próprio como Aquilo que eternamente tem de retornar, como um vir-a-ser que não conhece nenhuma saciedade, nenhum fastio, nenhum cansaço esse meu mundo dionisíaco do eternamente-criar-a-si-próprio, do eternamentedestruir-a-si-próprio, esse mundo secreto da dupla volúpia, esse meu "para além de bem e mal", sem alvo, se na felicidade do círculo não está um alvo, sem vontade, se um anel não tem boa vontade consigo mesmo [...] Esse mundo é a vontade de potência - e nada além disso! E também vós próprios sois essa vontade de potência - e nada além disso!
\end{abstract}

Nosso movimento atraiu outras pessoas tão sedentas quanto nós em explorar novos territórios do pensamento com as Filosofias Contemporâneas. Então, o grupo cresceu, abriuse a novos agenciamentos. Somos hoje vinte e cinco integrantes, pesquisadores/as e profissionais de áreas diversas, como: Pedagogia, Psicologia, Letras, Música, História, Geografia, Biologia, Matemática e Assistência Social. Sujeitos que se interessam por ler, pensar e compartilhar idéias, experiências, sensações, saberes, suspeitas, reflexões, indagações e que agem como intercessores uns dos outros, através de conversações ativadas pelo estudo de conceitos filosóficos do pensamento e obras de Foucault, Nietzsche e Deleuze.

Nesse sentido, o plano de imanência, ou seja, a razão de existir do grupo é o desejo de estudar as Filosofias Contemporâneas e suas possíveis articulações ou dobras em relação às ciências nos diferentes campos científicos, aos modos de vida, aos processos de subjetivação e as relações que estabelecemos cotidianamente. Promover encontros que façam fluir o pensamento por intercessões, ressonâncias, ecos, articulações, convergências, que, desejamos, 
tornem-se dispositivos para inspirar a escrita livre, a produção acadêmica e/ou práticas de pesquisa em diferentes áreas científicas, nas artes e na vida cotidiana.

Nesse artigo, buscamos cartografar o mapa que traçamos em nossa existência enquanto grupo, trazendo os conceitos e os modos pelos quais temos operado nossa maquinaria de pensamento, entendendo que se trata de uma colagem momentânea, uma montagem das nossas experimentações filosóficas, sempre em estado de devir.

\section{O plano de imanência que constitui nosso devir filosófico}

Filosofar na contemporaneidade, de acordo com Deleuze e Guattari (2000), não se trata de um exercício de contemplação do mundo das idéias como uma condição da racionalidade e existência humana requeridas por Platão e Sócrates na Antiguidade Grego Clássica. Também não pretende guiar-se conforme o pensamento moderno fundado em Kant e Descartes, criando um meta-discurso ou metalinguagem que explique outros domínios (como as artes e as ciências) e justifique critérios de legitimidade, veracidade de um discurso universalizante.

A filosofia é criação de conceitos, uma arte de formar, inventar, fabricar conceitos. Conceitos que se constituem de forma singular por uma complexidade de componentes representados diante de um problema colocado pelos filósofos num determinado tempo e espaço. Logo, “[...] é filósofo quem se torna filósofo” (DELEUZE, 1992, p. 37).

Como nos diz Nietzsche (2005), o filosofar histórico é necessário em contraposição a uma filosofia metafísica contemplativa. A filosofia desinteressada, apartada das condições históricas das existências humanas, prescreve verdades fechadas. Mas, tudo que se pronuncia acerca da existência humana não passa de um testemunho sobre determinados modos de existir num espaço e tempo delimitado. Pensar a existência humana historicamente significa tomar as vidas singulares na suas condições reais, sem julgamentos morais, sem preceitos verdadeiros que nos esquivem dos erros.

Partindo dessa perspectiva filosófica, no Projeto Filosofias Contemporâneas compartilhamos leituras e fomentamos um território de ressonâncias, agenciamentos e desvios em relação aos problemas/temas que interessam a cada um/a que vivencia essa experiência. Uma arte de filosofar singular e complexa que só pode ser suscitada entre amigos/as, pois a filosofia acontece no estabelecimento de encontros, intercessões, ecos, ressonâncias, articulações, agenciamentos, convergências de diferentes domínios científicos e das artes. Filosofar entre amigos, como diz Nietzsche (2012) que se tornam os melhores inimigos na 
nudez de uma relação de reciprocidade, mestres nas artes de falar e calar que provocam a vontade de potência uns nos outros.

$\mathrm{Na}$ arte de filosofar que assumimos como nosso plano de imanência, os conceitos tornam-se dispositivos que acionam as conversações e criam modos de pensar, constituindo um conjunto de multiplicidades e singularidades abertas a novas e constantes conexões, o que entendemos tratar-se de formações rizomáticas. Como esclarece Gallo (2003) acerca do conceito criado por Deleuze, o rizoma forma um mapa que pode ser cartografado, porém não possui uma origem, um início, pode ser acessado de diferentes pontos e remeter a outros tantos em seu território, cria entradas múltiplas, pontos de fuga, regiões insuspeitas, enfim, “[...] uma riqueza geográfica pautada na lógica do devir, da exploração, da descoberta de novas facetas" (GALO, 2003, p. 94).

\subsection{Conceitos: dispositivos que acionam o pensamento livre}

Conforme Deleuze e Guattari (2000), um conceito é um todo fragmentado, uma multiplicidade, uma articulação de elementos ou componentes distintos, heterogêneos mas inseparáveis que na ação filosófica funcionam como dispositivos que acionam a maquinaria do pensamento. Dispositivo que, para Foucault estabelece uma rede de relações entre elementos heterogêneos, práticas discursivas e não-discursivas, operadas para a formação de racionalidades que entram em ressonância ou contradição com outras já existentes e produzem novas epistemes (CASTRO, 2016).

Portanto, os conceitos têm uma história, são fabricados por meio de intercessões, uma vez que, “[...] é no nível de interferência de muitas práticas que as coisas se fazem, os seres, as imagens, os conceitos, todos os tipos de acontecimentos" (DELEUZE apud MACHADO, 2009).

Assim se constitui o duplo por meio da colagem, desembaraçando os conceitos de seus sistemas de origem. Cria-se o rizoma, sistema aberto que relaciona conceitos às circunstâncias em que se produzem relações entre eles. Forma-se o mapa de linhas que delineiam as coisas e os acontecimentos e estabelecem agenciamentos, linhas de fuga, movimentos de territorialização, desterritorialização e reterritorialização (DELEUZE, 1992).

Contra os que pensam "eu sou isto, eu sou aquilo", e que pensam assim de uma maneira psicanalítica (referência a sua infância ou destino), é preciso pensar em termos incertos, improváveis: eu não sei o que sou, tantas buscas ou tentativas necessárias, não-narcísicas, não-edipianas [...] O problema não é ser isto ou aquilo no homem, mas o antes o de um devir inumano, de um devir universal animal: não tornar-se por um animal, mas desfazer a organização humana do corpo, atravessar 
tal ou qual zona de intensidade do corpo, cada um descobrindo as suas próprias zonas, e os grupos, as populações, as espécies que o habitam" (DELEUZE, 1992, p. 21).

Esse entendimento nos leva, forçosamente, a interagir na multiplicidade das áreas científicas, a articular e conectar a filosofia com as artes e as ciências, campos distintos mas passíveis de constituir alianças na interlocução entre os diferentes saberes que potencializam o pensamento livre. Assim, o Grupo de Pesquisa Philos Sophias constitui sua existência para experimentar de outro jeito o lugar onde está situado, o que não é tarefa modesta, pelo contrário, confirma o desafio da autenticidade diante de um mundo que ainda busca uma perfeição das coisas, pessoas, é, na verdade, um trabalho instigante.

As motivações que trouxeram cada um/a mobilizam os estudos e compartilhamentos das leituras que reinventam histórias, pensamentos e relações. Experimentamos o diferente, movidos pela sede e o desejo de filosofar. Entendemos que nossas experimentações filosóficas configuram um território rizomático, pois:

[...] o rizoma conecta um ponto qualquer com outro ponto qualquer e cada um de seus traços não remete necessariamente a traços da mesma natureza; ele põe em jogo regimes de signos muito diferentes, inclusive estados de não signos. O rizoma não se deixa reconduzir nem ao Uno nem ao múltiplo. Ele não é o Uno que devém dois, nem mesmo que deviria diretamente três, quatro ou cinco etc. Ele não é o múltiplo que deriva do Uno, nem ao qual o Uno se acrescentaria $(n+1)$. Ele não é feito de unidades, mas de dimensões ou antes de direções movediças. Ele não tem começo nem fim, mas sempre um meio pelo qual ele cresce e transborda. Ele constitui multiplicidades lineares e $n$ dimensões, sem sujeito nem objeto, exibíveis num plano de consistência e do qual o Uno é sempre subtraído (n-1). Uma tal multiplicidade não varia suas dimensões sem mudar de natureza nela mesma e se metamorfosear. (DELEUZE; GUATTARI, 2017, p. 43)

Como nos dizem Deleuze e Guattari (2017, p.22-30) o rizoma possui certos princípios, sendo eles, a (1) conexão e heterogeneidade, ou seja, um rizoma pode ser um conjunto de pontos que não são fixos, mas estabelece diferentes conexões nos modos como ocorrem os agenciamentos; diferente do sistema arbóreo em que as raízes fixam e determinam os modos de pensamento, ação e relação de uma forma linear; (2) multiplicidade, é a não existência de uma unidade, nem do sujeito e nem do objeto, ou seja, as relações mais complexas acontecem na própria ação do pensar e nas dimensões que se criam nessa conexão; (3) ruptura assignificante, o rizoma forma-se de diferentes modos à medida que se territorializa, desterretorializa e reterritorializa, assim o pensamento se produz de diferentes formas em movimentos descontínuos operados por linhas de fuga; (4) princípio da cartografia e da decalcomania, segundo o qual o rizoma não se caracteriza por uma estrutura que possa ser 
palpável ou representada de modo finito, mas seu funcionamento pode ser cartografado como um mapa.

O mapa é aberto, é conectável em todas as suas dimensões, desmontável, reversível suscetível de receber modificações constantemente. Ele pode ser rasgado, revertido, adaptar-se a montagens de qualquer natureza, ser preparado por um individuo um grupo, uma formação social. Pode-se desenhá-lo em uma parede, concebê-lo como obra de arte, construí-lo como uma ação política ou como uma meditação. (DELEUZE; GUATTARI, 2017, p.30).

Portanto, nos encontros de compartilhamento de leituras, desenhamos um mapa de conexões múltiplas ativadas pelas Filosofias Contemporâneas que nos desafiam a um pensar singular plural, criando multiplicidades que tecem uma nova estética, a estética da vida que nos fala Foucault. Cada um é convidado a produzir um pensamento livre, abrindo linhas de fuga que nos solte de convicções definitivas, de nossas experiências e de nós mesmos, produzindo e articulando convergências, agenciamentos, deslocamentos nas leituras de mundo que vão configurando a existência do grupo ao existir, um mutante devir.

\section{Síntese Provisória}

Constituímos o Grupo Philos Sophias, traçamos nosso território filosófico integrando diferentes sujeitos que, em razão de suas distintas formações acadêmicas, produzem a complexidade das formas de pensamento, nas conversações. Com isso, não queremos estabelecer certezas, verdades universais, mas fazer funcionar múltiplas formas de pensamento, deslocamentos, experimentações que provoquem os sujeitos a falar em nome próprio, abertos a multiplicidades intensas, singularidades soltas.

Nossa vontade de potência, desde o início, foi o desejo pelo saber e de ver a vida pelas lentes desse outro olhar que reconhecemos bebendo no manancial da pluralidade. Com isso, objetivamos a construção de saberes e experiências voltadas a uma estética da existência que promova o cuidado de si na relação com os outros e com o mundo presente, promotora, tanto quanto possível, de exercitar o pensamento livre, técnicas parresistas que, conforme ensina Foucault (2004), permitam a cada indivíduo criar, ousar, correr riscos, escapar de códigos morais instituídos e governamentos do corpo, da alma e das relações sociais e políticas que impõem verdades absolutas.

A construção de conceitos filosóficos acontece a partir desse desejo, vontade de potencia que produz a arte de filosofar, de ir além. Somos seres únicos vivendo a multiplicidade que Deleuze, Nietzsche e Foucault nos instigam a pensar, a fabricar na arte de 
filosofar. Somos um grupo de amigos, os amigos da sabedoria: Philos Sophias. Cada um vem de um lugar, de diferentes experiências que se entrelaçam nesse emaranhado que nos constitui enquanto grupo, uma história permeada por rupturas de estruturas que possam engessar, tal a fruição de pensamentos singulares e múltiplos.

Filosofar não para constituir uma moral do "bem agir", mas para que cada um na relação com os outros crie uma reciprocidade capaz de produzir uma arte da existência, onde sejam produzidos agregados estéticos sensíveis à liberdade de ser, pensar e viver de cada elemento que constitui o grupo para um cuidar de si na relação com os outros, pois acreditamos que a beleza da existência está naquilo que cada um/a atribui e assumi para si como um viver belo (FOUCAULT, 2010).

\section{Referências}

CASTRO, E. Vocabulário de Foucault: um percurso pelos seus temas, conceitos e autores. $2^{\circ}$ ed. Belo Horizonte: Autêntica, 2016, 477 p. (Obra completa)

DELEUZE, G. Conversações. Trad. Peter Pál Pelbart. São Paulo: Ed. 34, 1992, 231 p. (Obra completa)

DELEUZE, G.; GUATTARI, F. O que é a filosofia? Trad. Bento Prado Jr. E Alberto Alonzo Munoz. São Paulo: Ed. 34, 1991, 282 p. (Obra completa)

Mil Platôs: capitalismo e esquizofrenia. Vol. 1. Trad. Ana Lúcia de Oliveira. Rio de Janeiro: Ed. 34, 2017, 127 p. (Obra completa)

FOUCALT, M. A hermenêutica do sujeito: Curso em Collége de France (1981-1982). Trad.Márcio Alves da Fonseca E Salma TannusMuchail. $3^{\circ}$ Ed. São Paulo: Martins Fontes, 2010, 506 p. (Obra completa)

GALLO, S. Deleuze \& a Educação. Belo Horizonte: Autêntica, 2003, 118 p. (Obra completa)

MACHADO, R. Deleuze, a arte e a filosofia. Rio de Janeiro: Jorge Zahar, 2009, 344p. (Obra completa)

NIETZSCHE, F. Humano, demasiado humano. Trad. Paulo César de Souza. São Paulo: Companhia das Letras, 2015, 315 p. (Obra completa)

Assim falava Zaratustra: um livro para todos e para ninguém. Trad. Antônio Carlos Braga. São Paulo: Lafonte, 2012, 285 p. (Obra completa)

O eterno retorno. In: NIETZSCHE, F. Obras incompletas. Trad. Rubens

Rodrigues Torres Filho. São Paulo, Ed. Nova Cultural Ltda, 1999, p. 439-450. (Capítulo de Livro)

QUINTANA, M.. Verso XXII. Caderno H. Porto Alegre: Alfaguara, 1973, 368 p. (Obra completa) 